\title{
A Variation of the Components' Separation Technique that Preserves the Semilunaris for Treatment of Abdominal Wall Deformities
}

\author{
Marcus Vinícius Jardini Barbosa ${ }^{1}$ Fábio Xerfan Nahas ${ }^{2}$ Lydia Masako Ferreira ${ }^{2}$ \\ ${ }^{1}$ Morphofunctional Laboratory of the Scholl of Medicine of \\ the University of Franca, Franca, São Paulo, Brazil, \\ 2 Department of Surgery, Division of Plastic Surgery of \\ the Federal University of São Paulo, São Paulo, Brazil \\ Indian J Plast Surg 2022;55:92-96.

\begin{abstract}
Address for correspondence
Marcus Vinícius Jardini Barbosa, MD, PhD, Morphofunctional Laboratory of the Scholl of Medicine of the University of Franca, Alameda dos Flamboyants, 700-Morada do Verde, Franca, SP 14404-409, Brazil (e-mail: drmbarbosa@gmail.com.br).
\end{abstract}

\begin{abstract}
Keywords

- abdominal wall

- hernia

- plastic surgery

The variation of the components' separation technique, which uses the anterior rectus sheath and the release of the oblique muscles, proved to be effective in tension reduction. This paper aimed to present the initial experience using a variation that preserves semilunaris through the incision of the lateral aspect of the rectus sheath. All of the 12 patients presented an abdominal wall defect that included incisional hernia, peritoneostomy, lateral implantation of the rectus muscle, and defect secondary to TRAM flap. The separation was done in the following stages: stage 1-anterior rectus sheath and stage 2-external oblique muscles. From the 12 patients, three presented early complications: seroma $(n=2)$ and epitheliolysis $(n=1)$. There were no recurrences or other late complications ( 48 months follow-up period). The separation of the anterior rectus sheath, and incision in the lateral recess to undermine the oblique muscles, allowed the treatment of abdominal wall defects, without late complications.
\end{abstract}

\section{Introduction}

Abdominal wall reconstructions are frequent and complex procedures in surgery practice in which the use of meshes continues to be preferred by general surgeons, but their use is not exempt from complications. ${ }^{1,2}$ Since the initial description of the components' separation technique by Ramirez et $\mathrm{al}^{3}{ }^{3} \mathrm{a}$ great number of variations were developed to treat different abdominal wall deformities. ${ }^{4,5}$ Among these variations, the separation of the anterior rectus sheath has been proved to be effective in abdominal wall defects at the infraumbilical level. ${ }^{6}$ The incision of the semilunaris to separate the external oblique muscles is a common stage of all technical variations, which could promote a weakness in the lateral aspect of abdominal wall with possibility to hernia formation. ${ }^{5,7}$ Mathes et $\mathrm{al}^{8}$ demonstrated the possibility to access the surgical plan be- tween the external and internal oblique muscles through the incision of the internal lateral aspect of the posterior rectus sheath. Barbosa et $\mathrm{al}^{9}$ described a cadaver study and a clinical case showing the effectiveness in tension reduction with the dissection of the anterior rectus sheath and the access of the surgical plane between the external oblique muscle and the internal oblique muscle through the internal incision of the lateral aspect of the rectus sheath. They also highlighted that it is possible to have tension reduction without creating a weakness at the linea semilunaris.

The aim of this study was to present the experience of our group among the treatment of different types of abdominal wall deformities, using the variation of the components' separation technique that utilizes the anterior rectus sheath and preserves the linea semilunaris to undermine the oblique muscles. published online

October 1, 2021
DOI https://doi.org/ $10.1055 / \mathrm{s}-0041-1735419$ ISSN 0970-0358.

\footnotetext{
(c) 2021. Association of Plastic Surgeons of India. All rights reserved. This is an open access article published by Thieme under the terms of the Creative Commons Attribution-NonDerivative-NonCommercial-License, permitting copying and reproduction so long as the original work is given appropriate credit. Contents may not be used for commercial purposes, or adapted, remixed, transformed or built upon. (https://creativecommons.org/ licenses/by-nc-nd/4.0/)

Thieme Medical and Scientific Publishers Pvt. Ltd., A-12, 2nd Floor, Sector 2, Noida-201301 UP, India
} 


\section{Case Reports}

This study was conducted in accordance with Helsinki guidelines, and all of the patients had signed an informed consent. Twelve patients $(n=12)$ of both genders were consecutively included in this study between May 2012 to May 2016.

\section{Surgical Technique}

All procedures were done by the same surgeon (senior author), with the patient in supine position under general anesthesia. Patients, who presented with a previous scar in the midline, have surgical access through it with lateral dissection of the skin and subcutaneous until the anterior axillary line $(n=5)$, to preserve the lateral blood supply of the intercostal and lumbar vessels. When a previous midline scar was not present or the patient presented with infraumbilical median scar with excess of skin, a classic abdominoplasty incision and undermining was done $(n=7)$. After the exposure of the abdominal muscles, the defect was treated, and the reconstruction occurred in two stages:

- Stage 1: A longitudinal incision was done next to the linea alba, with completely separation of the anterior rectus sheath (- Fig. 1).

- Stage 2: An internal incision on the lateral aspect of the rectus sheath along the e projection of the semilunaris, with separation of the surgical plane between the external and internal oblique muscles, laterally, until the anterior axillary line (stage 2--Figs. 2 and $\mathbf{3}$ ).

The posterior and anterior sheaths were closed in the midline, using a 3-0 nylon suture, to recreate the linea alba (-Fig. 4). Quilting sutures between the dermofat flap and the muscles were done, using 2-0 nylon suture, to reduce seroma formation. A suction drain was positioned, and the superficial layers were closed. The mean follow-up period was 48 months.

\section{Results}

The main characteristics of the sample were described in -Table 1. The abdominal wall defect included the

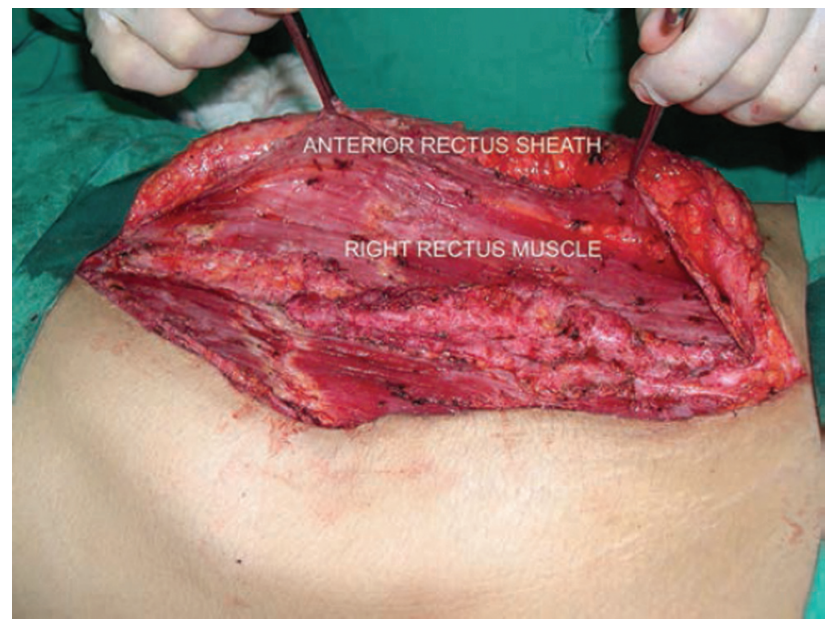

Fig. 1 Intraoperative aspect of the stage 1 (separation of the anterior sheath).



Fig. 2 Intraoperative aspect of the stage 2. The extremity of the forceps shows the lateral aspect of the rectus sheath to be incised.

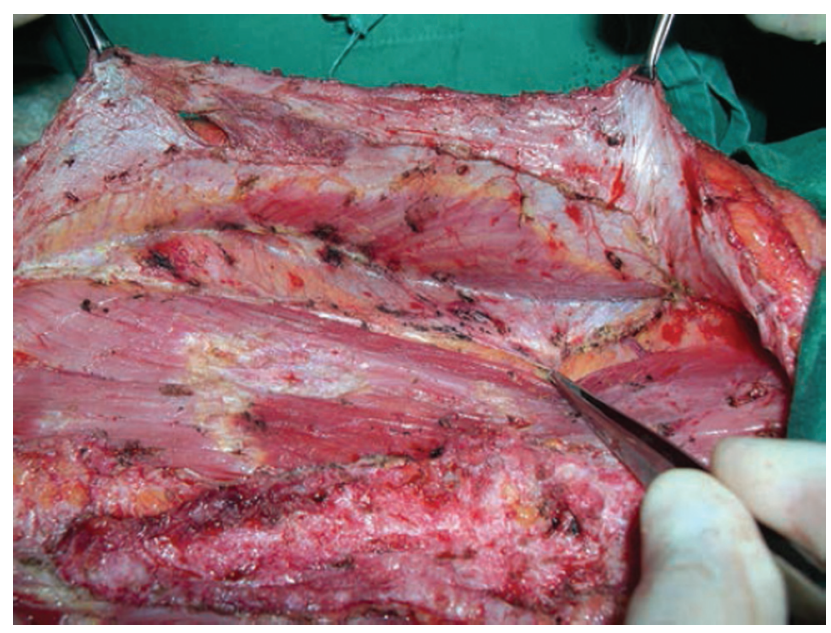

Fig. 3 Intraoperative aspect of the myoaponeurotic "set" compound by the anterior rectus sheath-external oblique muscle.



Fig. 4 Final aspect of reconstruction after both stages of dissection. 
Table 1 General aspect of the sample treated with the variation of the components separation technique that uses the anterior rectus sheath and preserves the semilunaris

\begin{tabular}{|l|l|l|l|l|l|l|l|}
\hline $\begin{array}{l}\text { Patient } \\
(\mathbf{n}=\mathbf{1 2})\end{array}$ & Ethnicity & $\begin{array}{l}\text { Age } \\
\text { (years) }\end{array}$ & Gender & $\begin{array}{l}\text { BMI } \\
\left(\mathbf{k g} / \mathbf{m}^{2}\right)\end{array}$ & Type of the defect & $\begin{array}{l}\text { Size of the } \\
\text { defect (length } \times \text { width) }\end{array}$ & $\begin{array}{l}\text { Follow-up } \\
(\mathbf{m o n t h s})\end{array}$ \\
\hline 1 & Afro descendant & 59 & $\mathrm{~F}$ & 27.30 & $\begin{array}{l}\text { Infraumbilical incisional } \\
\text { hernia }\end{array}$ & $11.0 \times 7.0$ & 72 \\
\hline 2 & Caucasian & 18 & $\mathrm{~F}$ & 25.11 & $\begin{array}{l}\text { Infraumbilical incisional } \\
\text { hernia }\end{array}$ & $7.0 \times 7.0$ & 72 \\
\hline 3 & Caucasian & 56 & $\mathrm{~F}$ & 33.20 & $\begin{array}{l}\text { Infraumbilical incisional } \\
\text { hernia }\end{array}$ & $17.0 \times 12.0$ & 48 \\
\hline 4 & Caucasian & 23 & $\mathrm{~F}$ & 23.70 & $\begin{array}{l}\text { Peritoneostomy with } \\
\text { mesh extrusion }\end{array}$ & $9.0 \times 4.0$ & 36 \\
\hline 5 & Caucasian & 30 & $\mathrm{~F}$ & 24.20 & $\begin{array}{l}\text { Peritoneostomy with } \\
\text { supraumbilical hernia }\end{array}$ & $10.0 \times 5.0$ & 72 \\
\hline 6 & Caucasian & 60 & $\mathrm{~F}$ & 30.01 & $\begin{array}{l}\text { Infraumbilical incisional } \\
\text { hernia }\end{array}$ & $12.0 \times 6.0$ & 72 \\
\hline 7 & Caucasian & 50 & $\mathrm{~F}$ & 31.20 & $\begin{array}{l}\text { Epigastric and infraum- } \\
\text { bilical incisional hernia }\end{array}$ & $10.0 \times 4.5$ & 48 \\
\hline 9 & Caucasian & 60 & $\mathrm{M}$ & 32.10 & $\begin{array}{l}\text { Infraumbilical incisional } \\
\text { hernia }\end{array}$ & $35.0 \times 25.0$ & 36 \\
\hline 10 & Caucasian & 35 & $\mathrm{~F}$ & 25.60 & Unilateral TRAM & $30.0 \times 5.0^{\mathrm{b}}$ & 36 \\
\hline 11 & Caucasian & 42 & $\mathrm{~F}$ & 24.20 & $\begin{array}{l}\text { Congenital lateral im- } \\
\text { plantation of the recti } \\
\text { muscles }\end{array}$ & $25.0 \times 5.5^{\mathrm{c}}$ & $\begin{array}{l}\text { ang } \\
\text { plantation of the recti } \\
\text { muscles }\end{array}$ \\
\hline 12 & Caucasian & 56 & $\mathrm{M}$ & 24.70 & $\begin{array}{l}\text { Infraumbilical incisional } \\
\text { hernia }\end{array}$ & $25.0 \times 12.4$ & 48 \\
\hline
\end{tabular}

Abbreviations: BMI, body mass index; TRAM, transverse rectus abdominis musculocutaneous.

${ }^{a}$ Nahas, 2001. ${ }^{11}$

${ }^{b}$ Dimensions of the rectus abdominis muscle.

'The length corresponds to the line alba.
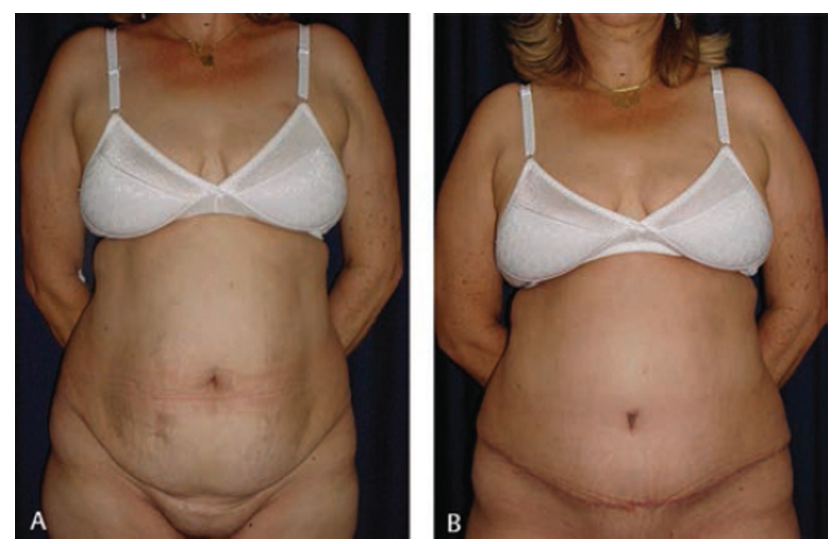

Fig. 5 A 46 year-old female patient with congenital lateral implantation of the recti muscles. (a) Preoperative frontal view. (b) 36 months postoperative frontal view.

following: incisional hernia with skin excess $(n=4)$, incisional hernia without skin excess $(n=3)$, peritoneostomy $(n=2)$, lateral congenital implantation of the rectus muscles ${ }^{10}(n=2)$, and after transverse rectus abdominis musculocutaneous (TRAM) flap $(n=1)$.
In all patients, the two stages of myoaponeurotic undermining were necessary, to obtain the lowest tension for midline closure.

Early complications included the following: seroma in two female patients and superficial skin necrosis in one male patient, who were treated clinically, with good results. There were no recurrences or other late complications along the 48 months follow-up period. The pre- and postoperative outcome of the technique is illustrated in -Figs. 5-7.

\section{Discussion}

The concept of the "components separation" technique was widely used and modified by many authors ${ }^{6,7}$ with the incision of the linea semilunaris, to release the external oblique muscles, seeming to be the common stage for all surgical variations. ${ }^{1,3,5}$ This line corresponds to the confluence of the aponeuroses of the oblique (external and internal) and transverse muscles, located on the lateral margin of the rectus abdominis muscle. ${ }^{4,6}$ However, an iatrogenic weakness in this important anatomical site could promote a new hernia formation. ${ }^{9}$ One of the variations of the 

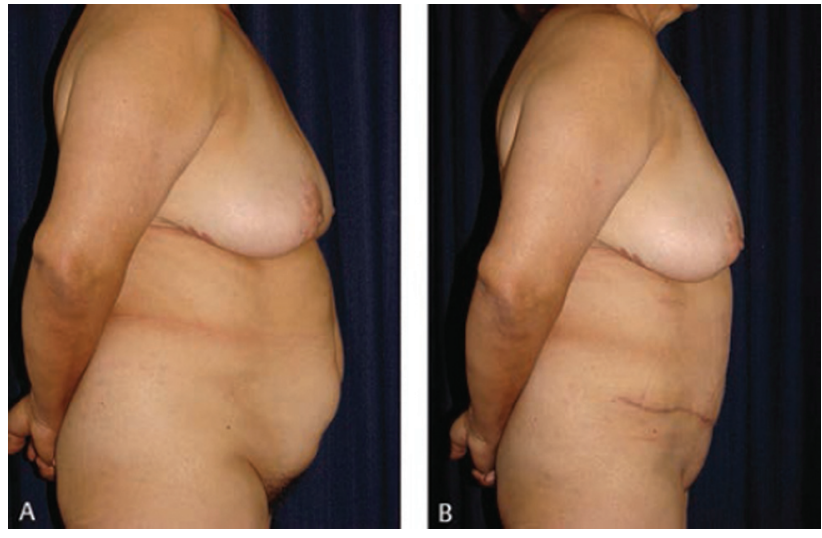

Fig. 6 A 56 year-old female patient with an infraumbilical incisional hernia due to a hysterectomy. (a) Preoperative profile view. (b) 36 months postoperative view.
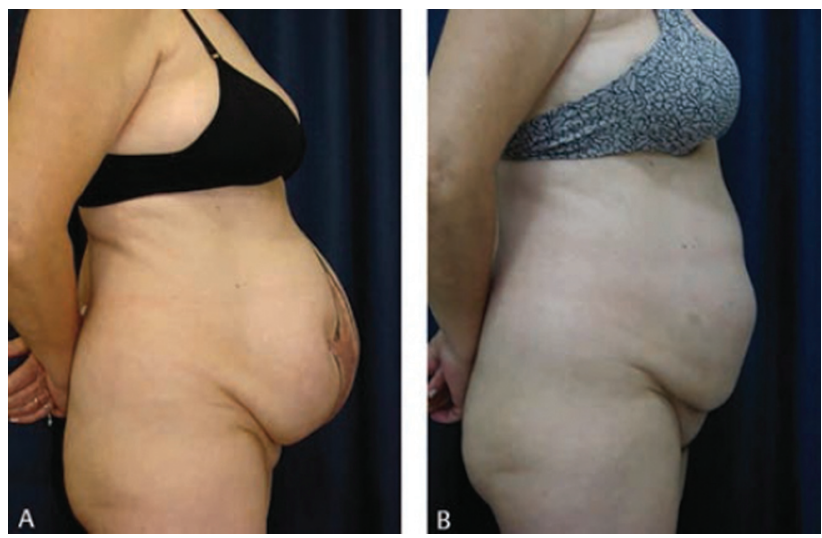

Fig. 7 A 54 year-old female patient with an infraumbilical incisional hernia due to a laparotomy. (a) Preoperative right profile view. (b) 48 months postoperative view.

components' separation technique had included the use of the anterior rectus sheath to treat abdominal wall defects, because of its continuity below the arcuate line. ${ }^{6}$

To avoid the incision of the semilunaris, after the separation of the posterior rectus sheath, Mathes et $\mathrm{al}^{8}$ described an internal incision of the lateral aspect of it to achieve the surgical plan between the external and internal oblique muscles. Considering that the posterior rectus sheath is not present below the arcuate line (where bellow only the transversalis fascia is present $),{ }^{9}$ the same dissection of the anterior rectus sheath could cover two important aspects of many abdominal wall reconstructions: the necessity to treat defects bellow the arcuate line, and the preservation of the semilunaris. This modified technique proved to be effective in tension reduction through a cadaver and clinical study by our group, ${ }^{6,9}$ which motivated us to expand the series. Although the use of the posterior approach of the components' separation technique associated with the release of the transversus abdominis has been shown to be effective, ${ }^{1,7}$ as the anterior open approach, ${ }^{5}$ it is known that one of the factors for improving the result is related to the team's learning curve.
According to the literature, the arterial supply of the abdominal flap and muscles are replaced by collateral circulation from the intercostal arteries, lumbar arteries that run between the internal oblique muscle and transverse muscle, and the dermal plexus. ${ }^{6}$ In this kind of procedure, the management of perforating arteries followed the same pattern as in the classic components' separation technique and the TRAM flap procedure. However, many authors such as Elhage et $\mathrm{al}^{7}$ have described technical modifications to minimize damage to the perforator vessels.

All the 12 patients had their small or medium abdominal wall defects treated with both proposed stages of dissection bilaterally. It probably occurred as the anterior rectus sheath is more resistant to medial traction because of the costal insertions ${ }^{6}$ and the greater amount of collagen fibers below the arcuate line. ${ }^{9}$

The most frequent early complications are related to the wound, as well as hematoma and seroma, while recurrence is the most feared late complication..$^{1-3,5}$ In the present study, only early complications occurred, which were treated clinically with good results. Bhave demonstrated that the evidence in favor of the use of drains is insufficient. ${ }^{10}$ However, we chose to use it due to the large detachment to monitor the occurrence of hematoma. There were no recurrences along the 48 months follow-up period.

The use of synthetic meshes to treat large or giant abdominal wall defects is well-established because of the reduction of the recurrence rate. ${ }^{1,5,8}$ However, despite the wide use of synthetic meshes, it could be avoided when patients presented with small or medium defects or associated with local flaps, ${ }^{2}$ because it is not exempt from complications, ${ }^{4}$ and the failure rate in any surgical procedure is related to the experience of the surgical team. ${ }^{7}$ The purpose of the present study was not to abolish the use of synthetic meshes, established mainly in the treatment of giant hernias, but to show another safe, anatomical, and functional option for the treatment of different abdominal wall defects, which can even be applied in cases of small and medium abdominal wall defects. The focus of the paper is to rationalize the use of meshes and not eliminate them.

The study presents some limitations, and despite the good results, it is an initial experience with a small sample, and a short follow-up period, which will be expanded and presented in the future.

In conclusion, the use of both stages was effective to treat different supra and infraumbilical abdominal wall defects. The use of the anterior rectus sheath seems to be more reasonable to treat infraumbilical defects, and the preservation of the semilunaris is an important aspect to avoid iatrogenic hernia.

Institution from Which the Work Originated

School of Medicine, University of Franca, São Paulo, Brazil.

Funding

The authors declare that they do not have any commercial interest in the subject of study or in the source of any financial or material support. 


\section{Conflict of Interest \\ None declared.}

\section{References}

1 Scheuerlein H, Thiessen A, Schug-Pass C, Kückerling F. What do we know about component separation technique for abdominal wall hernia repair? Front Surg 2018;5; 24

2 Cavadas PC, Téllez-Palacios D. Abdominal wall reconstruction with a free fibula flap after internal extended hemipelvectomy. Indian J Plast Surg 2020;53(01):131-134

3 Ramirez OM, Ruas E, Dellon AL. "Components separation" method for closure of abdominal-wall defects: an anatomic and clinical study. Plast Reconstr Surg 1990;86(03):519-526

4 Maloney SR, Schlosser KA, Prasad T, et al. The impact of component separation technique versus no component separation technique on complications and quality of life in the repair of large ventral hernias. Surg Endosc 2020;34(02):981-987

5 Naran S, Shakir S, Shestak KC, Russavage JM, Nguyen VT. Components separation for abdominal wall reconstruction in the recalcitrant, high-comorbidity patient - A review of 311 singlesurgeon cases. Ann Plast Surg 2018;80(03):262-267
6 Barbosa MV, Nahas FX, Garcia EB, Ayaviri NA, Juliano Y, Ferreira LM. Use of the anterior rectus sheath for abdominal wall reconstruction: a study in cadavers. Scand J Plast Reconstr Surg Hand Surg 2007;41(06):273-277

7 Elhage SA, Marturano MN, Prasad T, et al. Impact of perforator sparing on anterior component separation outcomes in open abdominal wall reconstruction. Surg Endosc 2021;35(08): 4624-4631

8 Mathes SJ, Steinwald PM, Foster RD, Hoffman WY, Anthony JP. Complex abdominal wall reconstruction: a comparison of flap and mesh closure. Ann Surg 2000;232(04):586-596

9 Barbosa MV, Nahas FX, de Oliveira Filho RS, Ayaviri NA, Novo NF, Ferreira LM. A variation in the component separation technique that preserves linea semilunaris: a study in cadavers and a clinical case. J Plast Reconstr Aesthet Surg 2010;63(03):524-531

10 Bhave MA. Can drains be avoided in lipo-abdominoplasty? Indian J Plast Surg 2018;51(01):15-23

11 Nahas FX. An aesthetic classification of the abdomen based on the myoaponeurotic layer. Plast Reconstr Surg 2001;108(06): 1787-1795 